\title{
Spatio-temporal variation in soil seed banks under contrasting grazing regimes following low and high seasonal rainfall in arid Namibia
}

\author{
N. Dreber ${ }^{\mathrm{a}, *}$, K.J. Esler ${ }^{\mathrm{b}, \mathrm{c}}$ \\ ${ }^{a}$ Biodiversity, Evolution and Ecology of Plants, Biocentre Klein Flottbek and Botanical Garden, University of Hamburg, Ohnhorsstrasse 18, 22609 Hamburg, Germany \\ ${ }^{\mathrm{b}}$ Department of Conservation Ecology E' Entomology, Stellenbosch University, Private Bag x1, Matieland, 7602, South Africa \\ ${ }^{\mathrm{C}}$ Centre for Invasion Biology, Stellenbosch University, Private Bag x1, Matieland, 7602, South Africa
}

\section{A R T I C L E I N F O}

\section{Article history:}

Received 8 February 2010

Received in revised form

16 September 2010

Accepted 20 September 2010

Available online 14 October 2010

\section{Keywords:}

Degradation

Diaspore size

Microsite

Seed density

Spatial pattern

Species richness

\begin{abstract}
A B S T R A C T
In arid rangelands, soil seed bank characteristics vary with rainfall patterns, livestock pressure and habitat heterogeneity. We investigated this issue by assessing spatio-temporal patterns in soil seed bank density and richness in a degraded (heavy grazing) and non-degraded (light grazing) Nama Karoo ecosystem. To account for variation in seed distribution, different microsites were compared, and the effect of diaspore size on the patterning analyzed. Long-term heavy grazing increased seed densities and species richness of the soil seed bank by favoring small-seeded and tiny-seeded annual species. The spatial patterning of the soil seed bank was, however, similar to that found under sustainable grazing. The overall seed distribution was dictated by the small-scale environmental heterogeneity, which interacted with diaspore size. Our results suggest that the degraded environment is still efficient in controlling secondary dispersal and retaining seeds. This is through low stature barriers like surface rocks, which replace the function of grazing-sensitive perennial grasses in trapping and storing small diaspores. Soil seed banks were persistent and accumulated readilygerminable seeds over time. Observed temporal pattern across the study sites indicates that both condition and sequence of preceding rainfall seasons are likely to have a profound effect on soil seed banks of subsequent years.
\end{abstract}

(c) 2010 Elsevier Ltd. All rights reserved.

\section{Introduction}

Patterns in soil seed banks from arid and semiarid ecosystems are highly variable in space and time and linked to factors that influence seed production, mortality and spatial distribution (Kemp, 1989). In Namibia, both drought cycles (Msangi, 2004) and overgrazing (Klintenberg and Seely, 2004) are primary drivers of dryland degradation. Together these drivers can result in a broadscale restructuring of vegetation and a high fine-scale variation in resources such as seeds, which play a central role in degradation of arid and semiarid ecosystems (Peters et al., 2006). Therefore, understanding the impact of environmental changes in relation to grazing on soil seed banks is highly important for conservation,

\footnotetext{
* Corresponding author. Tel.: +49 4042816 219; fax: +49 4042816539.

E-mail addresses: n.dreber@botanik.uni-hamburg.de, n.dreber@gmx.de (N. Dreber), kje@sun.ac.za (K.J. Esler).
}

grazing management, and restoration purposes (Jones and Esler, 2004; Kassahun et al., 2009; Osem et al., 2006).

The high degree of spatial heterogeneity in structural and compositional properties of soil seed banks from arid and semiarid environments is mainly driven by patch scale heterogeneity in vegetation cover. It governs the capability to trap dispersing seeds, resulting in distinct patterns of seed accumulation (Bertiller, 1998; Guo et al., 1998; Quevedo-Robledo et al., 2010). In addition, physical soil properties and low-stature natural obstructions account for much of small-scale variation in seed deposition (DeFalco et al., 2009; Reichman, 1984), which is further affected by processes like directed dispersal, granivory or decay (Kemp, 1989; Nathan and Muller-Landau, 2000). Temporal changes therein relate to interannual climatic variability (Quevedo-Robledo et al., 2010).

In rangelands, the magnitude of overall heterogeneity in soil seed banks is strongly influenced by livestock pressure through selective grazing and disturbance-related environmental changes (Kassahun et al., 2009; Kinloch and Friedel, 2005a; Solomon et al., 2006). The size and spatial patterning of soil seed banks directly 
relate to changes in palatable plant cover, soil stability and availability of seed traps (Bertiller, 1998; Kinloch and Friedel, 2005b), but also compositional changes in the vegetation (Kinucan and Smeins, 1992; Navie et al., 1996). With the structural and compositional changes of the biophysical environment, selections for size traits occur that permit plants to increase in abundance (Osem et al., 2006). For example, high livestock pressure favors annuals, which tolerate or avoid intense grazing and trampling through various adaptations, such as prostrate growth and small seeds, which become easily buried (Navie and Rogers, 1997). During secondary dispersal, seed traits interact with microsite characteristics, thus determining where a moving seed comes to rest (Chambers, 2000). Diaspore mass as a proxy of seed size is an easyto-measure trait which has provided evidence of shifting patterns of seed distribution in response to spatial heterogeneity (Guo et al., 1998; Reichman, 1984) and grazing (Osem et al., 2006).

In the grassy tall shrublands of south-central Namibia, land degradation is a common problem, particularly in communal areas with their open access, unfenced pastures. Previous studies in the area found that strong competition for natural resources among communal farmers and inappropriate governance structures has resulted in poor range management and high stocking rates (Falk, 2008). Over time, this led to extended bare patches and a shift in vegetation composition from predominantly palatable perennials towards unpalatable annuals (Kuiper and Meadows, 2002). Today, the reduced vegetation cover, particularly that of perennial grasses, strongly affects hydrological processes such as an increase in runoff (Popp et al., 2009). The associated redistribution of resources and loss of soil by erosion is intensified by heavy trampling. Together these processes are assumed to lessen the capacity of the system to maintain a soil seed bank suitable for vegetation regeneration (Petersen, 2008).

We investigated this issue in the above-mentioned rangelands using the fence-line contrast approach, which allows analysis of long-term consequences of different grazing regimes on the environment. The study addresses the effects of contrasting grazing regimes on the structure and spatial patterning of soil seed banks considering both the role of available microsites (shrubs, low stature barriers and bare ground) and their interaction with diaspore size in determining seed distribution. We hypothesized that (i) long-term, severe and uncontrolled grazing alters soil seed bank structure, i.e. changes in seed densities and species richness, (ii) structural changes in the soil seed bank are apparent over different microsites, and (iii) spatial patterns in seed distribution differ between sites due to a dysfunction of the overgrazed environment in trapping and accumulating seeds at the small scale. We further expected that diaspore size-fractions in the soil seed bank would show varying response to the grazing regime and the associated quality of microsites present. As the prevailing stochastic climate is a primary source of overall variation, we compared patterns following a good rainfall season and a subsequent dry year.

\section{Materials and methods}

\subsection{Description of the study sites}

The study was conducted in Nama Karoo rangelands of the Karas region, south-central Namibia. Adjacent study sites were located in two Biodiversity Monitoring Observatories of the BIOTA Southern Africa project, about $20 \mathrm{~km}$ north of Keetmanshoop $\left(26^{\circ} 24.0717^{\prime} \mathrm{S}, 18^{\circ} 1.2905^{\prime} \mathrm{E}, 1100 \mathrm{~m}\right.$ a.s.l.). One site was situated in a 261 ha camp of the state research farm Gellap-Ost which has a history of sustainable, rotational grazing for over 70 years with mixed herds of mainly sheep (e.g. Karakul and Dorper) but also a few Boergoats and cattle. The camp is largely understocked with on average only up to a third of the total recommended stocking rate of the agricultural extension office of 6 ha/Small Stock Unit (SSU). In the present study, the camp acts as reference site for a grassy shrubland in natural condition (hereafter referred to as REF). Separated by a fence, the second site is located directly adjacent to REF on the Nabaos communal land, which has an extent of approximately 3500 ha. Since a change in land tenure from commercial to communal in the late 1970s, Nabaos has been exposed to continuous and uncontrolled grazing mainly by Boergoats but also some sheep and donkeys. The rangeland is overstocked with on average about $3 \mathrm{ha} / \mathrm{SSU}$. Because of prominent indicators of land degradation on Nabaos, this site is considered degraded and referred to as DEG.

The climate is arid with summer rain averaging $150 \mathrm{~mm}$ per year and an inter-annual coefficient of variation about $70-80 \%$ (Mendelsohn et al., 2002). The peak rainfall month is February. The mean annual temperature is $22{ }^{\circ} \mathrm{C}$, while temperatures during the germination season regularly exceed $35^{\circ} \mathrm{C}$. Soils are Regosols and Cambisols, derived from shale and sandy-loamy colluvial parent material, on which a 'desert pavement' of fine to coarse gravel has developed. Patches of sandy soils are interspersed with loamy ridges that are prone to crusting.

The vegetation type on REF is physiognomically characterized as a savanna-like open grassy shrubland and typical for the Nama Karoo Biome (Palmer and Hoffman, 1997). Shrubs, forbs, and grasses dominate the vegetation cover in dissected plains. The shrubby tree Boscia foetida and the shrubs Phaeoptilum spinosum and Lycium spp. constitute the most prominent portion of woody vegetation (nomenclature following Germishuizen and Meyer, 2003). The inter-shrub matrix is dominated by the perennial grasses Stipagrostis uniplumis and Stipagrostis hochstetteriana, with mainly upright forbs growing between the tussocks. On DEG, severe grazing favors the growth of the shrubs Rhigozum trichotomum and Calicorema capitata, annual pioneer grasses like Aristida adscensionis and Schmidtia kalahariensis over perennial grasses, and prostrate forbs in the inter-shrub matrix. Over the study period, the mean vegetation cover at a $1000-\mathrm{m}^{2}$ scale was $17.7 \%$ on $\mathrm{REF}$ and $11.3 \%$ on DEG with perennial grasses accounting for most of the difference (REF: 10.6\%; DEG: 0.01\%).

\subsection{Soil seed bank sampling}

On both sides of the fence, i.e. on REF and DEG, three soil seed bank sampling areas 1 ha in size and of homogeneous vegetation were chosen corresponding to biodiversity monitoring plots of the BIOTA Southern Africa project (Appendix 1). To avoid confounding effects of landscape heterogeneity and to reduce inter-site variability, habitats similar in geology (shale bedrock), soil unit (Cambisol) and topography (plains, inclination $1-2 \%$ to $\mathrm{NW}$ ) were chosen for comparison. All sampling areas were at least $600 \mathrm{~m}$ away from the next water source for livestock, and between $200 \mathrm{~m}$ and $500 \mathrm{~m}$ away from the bordering fence.

As recommended by Dreber (in press), soil sampling was conducted in late January 2007 and 2008 before the upcoming summer rains and the onset of any germination event to capture both the transient and persistent soil seed banks. Therefore, the cohort of seed from the previous season's (March-May) seed-set, which had experienced at least one winter stratification event, was included in the estimates. Precipitation in the rainy season 2005/2006 (October to April) was above average $(335.6 \mathrm{~mm}$ ), while in the season $2006 / 2007$ it was below average $(77.0 \mathrm{~mm})$. Thus, sampling followed two extreme and contrasting rainy seasons. Due to the water shortage in 2007, hardly any seed-set occurred, and most 
soil-stored seeds sampled in 2008 had run through at least two winter stratification cycles.

To determine the effect of spatial heterogeneity on seed distribution, three microsites were sampled: (i) shrub understoreys, termed 'canopy' (CAN), (ii) small physical barriers in the inter-shrub matrix, termed 'obstacles' (OBS), and (iii) bare ground (BG). OBS included low-size permanent structures able to trap ground-drifting seeds, i.e. grass tussocks, surface rocks $(>8 \mathrm{~cm}$ longest dimension), deadwood, and soil depressions. While the mean cover of CAN at the $1000-\mathrm{m}^{2}$ scale was similar across the fence-line (REF: $1.72 \%$; DEG: $1.84 \%$ ), proportions of single components in the inter-shrub matrix varied in response to the grazing regime. A small-scale survey at a $1-\mathrm{m}^{2}$ scale at time of soil seed bank sampling revealed that the OBS-component 'grass tussock' was significantly higher in cover on REF, while 'stones' were more prominent at DEG. Similarly, litter (including 'deadwood') was more prominent at REF, whereas bare ground as microsite was more abundant at DEG (Appendix 2). Presence of litter also provides an indirect indication of 'soil depressions' which trap ground-drifting material.

Per sampling area and year, three $100 \mathrm{~m}$ transects were established running parallel to the main topographic gradient in NW direction (in total nine transects per grazing regime). The starting point of each transect was located at random. OBS and BG were sampled systematically and alternately along the transects at regular intervals of $10 \mathrm{~m}$ in $1-\mathrm{m}^{2}$ plots. CAN was sampled under 10 shrubs per sampling area with two diameters of minimum $80 \mathrm{~cm}$ and a canopy close to the ground (Appendix 1). Due to the low shrub density, i.e. approximately 10-12 shrubs of that size per hectare, selection could not follow any randomized design. Total sampling points were 30 for CAN, 45 for OBS and 45 for BG per grazing regime and year.

At the study sites, about $80 \%$ of the germinable soil seed bank is located in the top $4 \mathrm{~cm}$ of soil (Dreber, in press), and accordingly the soil seed bank of deeper layers was not included in this study. At each sampling plot (1- $\mathrm{m}^{2}$ plot/shrub) five replicate soil cores $(5.5 \mathrm{~cm}$ in diameter $\times 4 \mathrm{~cm}$ deep, total area sampled: $119 \mathrm{~cm}^{2}$ ) were collected (Appendix 1) and material pooled (total volume: $475 \mathrm{~cm}^{3}$ ). OBS samples were taken from the base of tussocks and surface rocks, underneath deadwood, and in central position of depressions. The number of soil cores taken at one of these obstacles was proportional to their presence in the sampling plot. For example if two tussocks and one rock were in the plot, a total of three soil cores were taken from the base of the tussocks and two close to the rock. CAN samples were taken mid-way between shrub center and canopy edge in $70^{\circ}$ steps all around.

\subsection{Seedling emergence trials}

Soil samples were sieved through a $2-\mathrm{mm}$ mesh sieve to reduce the sample by removing stones and coarse plant fragments. The retained material was screened for seeds $>2 \mathrm{~mm}$ and these were returned to the sieved sample. Each sample was thoroughly stirred, and spread out to a depth of about $13 \mathrm{~mm}$ (depending on the sample volume after sieving) in four $9 \mathrm{~cm} \times 9 \mathrm{~cm}$ plastic trays on top of $5 \mathrm{~mm}$ of autoclave-sterilized sand covering a $70 \mathrm{~mm}$ deep layer of steam-sterilized sand-peat mix. The sand-peat mix was limed to a $\mathrm{pH}$ of $6.5-7$, similar to values measured in the field. Trays were placed in random arrangement in a greenhouse at the University of Hamburg and kept moist under controlled conditions, with a diurnal cycle of $14 \mathrm{~h}$ light at $30{ }^{\circ} \mathrm{C}$ and $10 \mathrm{~h}$ darkness at $17{ }^{\circ} \mathrm{C}$. These light/ temperature germination conditions proved to be effective in a previous study from this location (Dreber, in press). The number of emerged seedlings was counted daily. As soon as possible, seedlings were removed from the trays to preclude interaction effects on the germination of other viable seeds. For identification purposes, reference seedlings were replanted in separate trays until identification was possible at least at genus level. After 8-12 weeks, when germination rates approached zero, samples were stirred to move buried seeds nearer the surface causing a second germination surge. Germination tests continued until no new seedlings occurred after one week, which was 20 weeks after tests started.

\subsection{Diaspore size}

Weight of the seed, including appendages and enclosing structures, was used as a measure of diaspore size. In April 2009, diaspores of the most common species present in the germinable soil seed bank (about 80\%) were collected in the standing vegetation at the study sites. Mature diaspores were taken from at least 10 individuals per species, air-dried and stored under low humidity, ambient temperature conditions in the dark until measurements in September 2009. Diaspore size was calculated as the mean weight of a composite sample of 90-100 diaspores per species (sensu Chambers et al., 1991). Before weighing, diaspores were oven-dried for $48 \mathrm{~h}$ at $60^{\circ} \mathrm{C}$. Diaspores were classified into groups similar to seed mass categories used by Osem et al. (2006): tiny $=<0.3 \mathrm{mg}$, small $=0.3-0.9 \mathrm{mg}$, medium $=1-5 \mathrm{mg}$, and large $=>5 \mathrm{mg}$.

\subsection{Statistical analyses}

Univariate analyses of variance (ANOVAs) were conducted to test main effects of grazing regime (site) and/or microsite on species richness and seed density of the germinable soil seed bank, and diaspore sizes. Tukey's HSD tests were applied for pairwise comparisons across microsites after obtaining a significant ANOVA For spatio-temporal effects on soil seed bank data a repeatedmeasures ANOVA was conducted with 'year' as repeated variable, and 'site' and 'microsite' as between-subject factors. As the repeated -measure variable had only two levels (year 1 and year 2) assumption of sphericity was met, and thus an unadjusted $F$-test was used. Checks for assumptions of ANOVA were done visually according to Quinn and Keough (2002), and no violations detected after square-root transformation of soil seed bank data, and log-transformation of diaspore size data. Results displayed are untransformed values.

Generalized linear models (GLM) based on Poisson regressions with log-link function and correction for overdispersion (Quinn and Keough, 2002) were used in cases data transformations did not account for normality and variance homogeneity. With GLMs we tested the yearly effect of grazing regime on seed numbers per species in the soil seed banks, and the effect of microsites on the spatial distribution of each diaspore size category. In addition, the chi-square test of association (Pearson's $\chi^{2}$ statistic) was used to calculate the relationship between total seed numbers per diaspore size category and type of microsite following Dytham (2003). Raw counts of germinants within the single diaspore size categories were pooled for both years per site and microsite, and associations interpreted graphically and by comparisons of observed and expected values after a significant chi-square test. All statistical analyses were conducted using SPSS 15.0.

Descriptive statistics (means, variances, and variance-to-mean ratios $\left(s^{2} / \bar{x}\right)$ ) were used to express the degree of spatial seed aggregation per site and life forms with data from all microsites pooled. 

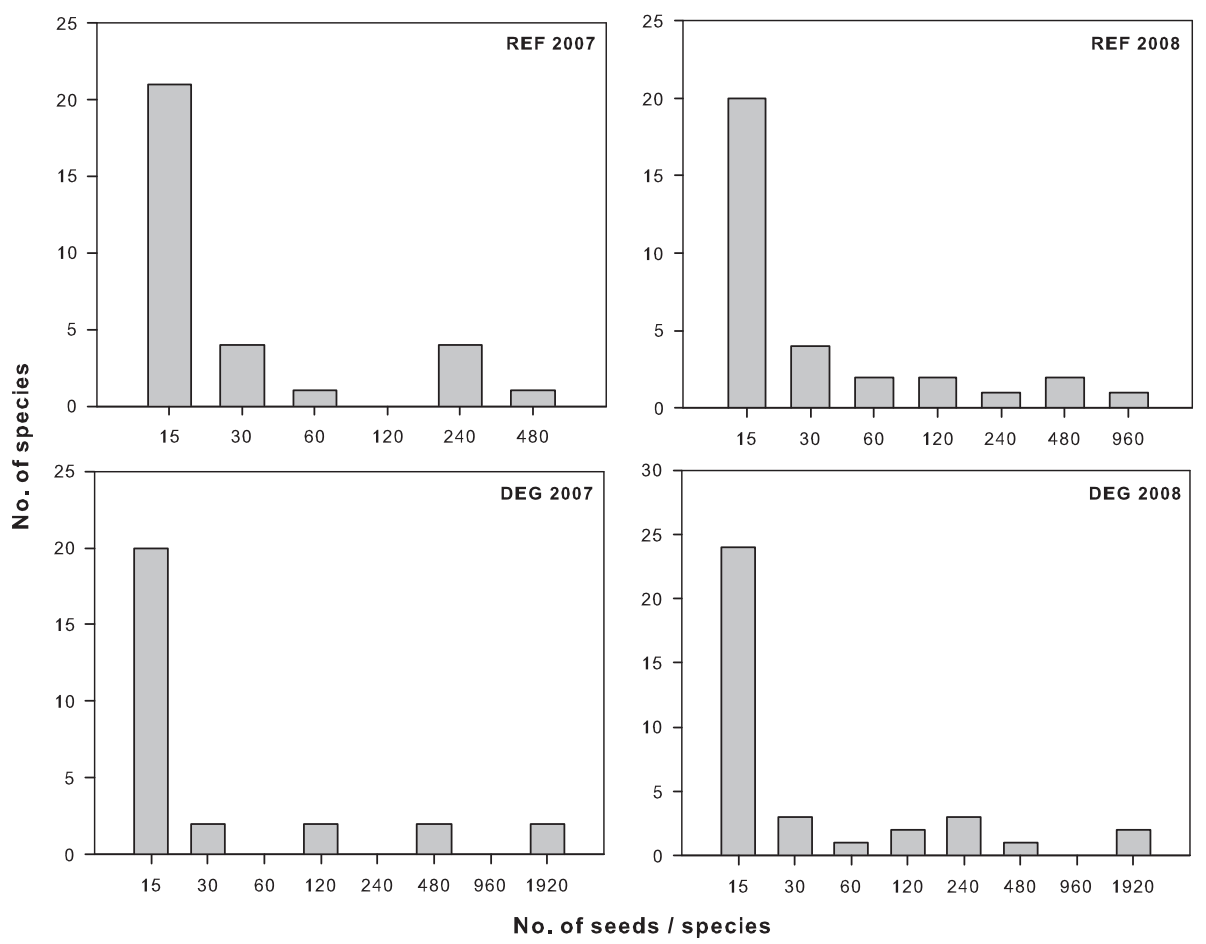

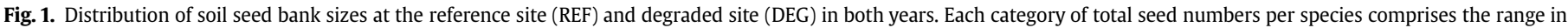
between two categories, i.e. $15=1-15,30=16-30,60=31-60$, and so on.

\section{Results}

In total, 5207 seedlings comprising 36 plant species germinated from the soil seed bank sampled in 2007 on REF and DEG. In contrast, more seeds and species were detected in the germinable soil seed bank of 2008 with a total of 6673 seedlings and 45 species recorded for both sites.

\subsection{Site effects}

Under both grazing regimes, most species had small soil seed banks ( $<15$ individuals), while only a few species had medium sized (30-120 individuals) and large soil seed banks ( $>120$ individuals) per year (Fig. 1). Accordingly, the mean number of seeds per species did not differ significantly between REF and DEG either in 2007, or in 2008 (GLM: Wald- $\chi^{2}=2.1, p=0.145$ for 2007 , Wald- $\chi^{2}=0.8$, $p=0.364$ for 2008 ) (Table 1 ).

The index of seed dispersion $\left(s^{2} / \bar{x}\right)$ revealed an overall clumped pattern on REF and DEG over the sampling years (Appendix 3). Similarly, variance-to-mean ratios of life forms ranged from 0.97 to 26.46 on REF, and from 0.97 to 41.24 on DEG indicating a predominantly aggregated distribution. A tendency for random distribution was found for dwarf shrubs in general, shrubs on REF and perennial grasses on DEG but in these cases the index was not reliable due to too low seed numbers (Appendix 3).

Species richness and seed density were significantly affected by site (i.e. grazing regime) with the mean number of species per sample point and the mean number of seeds $\mathrm{m}^{-2}$ being higher on DEG compared to REF in both years (Tables 1 and 2). The soil seed bank of DEG contained up to 28155 seeds $\mathrm{m}^{-2}$ with averages of 2651-3179 seeds $\mathrm{m}^{-2}$ over the years. Mean seed densities per $\mathrm{m}^{2}$ on REF varied between 964 and 1453 seeds only, with a maximum of 8913 seeds $\mathrm{m}^{-2}$.

On both sites, the diaspore size of soil seed bank species across the sampling years varied between $0.038 \mathrm{mg}$ and $49.371 \mathrm{mg}$ (mean size: $\mathrm{REF}=2.0 \mathrm{mg}$, DEG $=2.7 \mathrm{mg}$ ). Differences between sites were not significant (ANOVA REF 2007 vs. DEG 2007: $F=0.407, p=0.527$, REF 2008 vs. DEG 2008: $F=0.000, p=0.992$ ).

\subsection{Microsite effects}

Microsite had an overall significant effect on richness and density of the soil seed banks (Table 2). At both sites and over both years, there was a general decline in mean species numbers and

Table 1

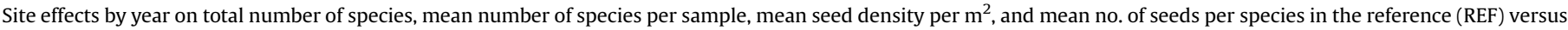
degraded (DEG) site. Means are given with \pm 1 SE.

\begin{tabular}{|c|c|c|c|c|}
\hline & 2007 & & 2008 & \\
\hline Soil seed bank attributes & REF & DEG & REF & DEG \\
\hline Total no. of species & 31 & 28 & 32 & 36 \\
\hline Mean no. of species $(n=120)$ & $3.3 \pm 0.2^{\mathrm{a}}$ & $4.5 \pm 0.2^{\mathrm{b}}$ & $4.0 \pm 0.2^{\mathrm{a}}$ & $5.5 \pm 0.3^{b}$ \\
\hline Mean seed density $/ \mathrm{m}^{2}(n=120)$ & $963.5 \pm 107.5^{\mathrm{a}}$ & $2651.0 \pm 262.8^{\mathrm{b}}$ & $1452.9 \pm 122.3^{a}$ & $3179.3 \pm 202.4^{\mathrm{b}}$ \\
\hline Mean no. of seeds/species & $43.6 \pm 17.5^{\mathrm{a}}$ & $132.3 \pm 67.6^{\mathrm{a}}$ & $62.6 \pm 2.3^{\mathrm{a}}$ & $122.2 \pm 3.0^{\mathrm{a}}$ \\
\hline
\end{tabular}

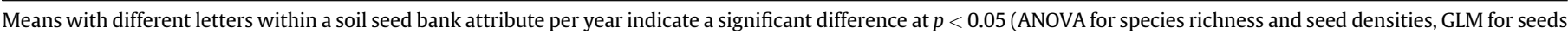
per species). 
Table 2

Effects of grazing regime (site), microsite, and year on species richness and seed density on the germinable soil seed bank. Repeated-measure ANOVA with 'year' as repeated variable.

\begin{tabular}{|c|c|c|c|c|c|c|}
\hline & \multicolumn{3}{|c|}{ Species richness } & \multicolumn{3}{|c|}{ Seed density } \\
\hline & df & $F$ & $p$ & df & $F$ & $p$ \\
\hline Site & 1 & 61.88 & $<0.001$ & 1 & 151.61 & $<0.001$ \\
\hline Microsite & 2 & 119.06 & $<0.001$ & 2 & 86.89 & $<0.001$ \\
\hline Site $\times$ Microsite & 2 & 1.2 & 0.303 & 2 & 3.58 & 0.029 \\
\hline Year & 1 & 26.69 & $<0.001$ & 1 & 23.66 & $<0.001$ \\
\hline Year $\times$ Site & 1 & 0.06 & 0.803 & 1 & 0.15 & 0.704 \\
\hline Year $\times$ Microsite & 2 & 9.07 & $<0.001$ & 2 & 3.18 & 0.044 \\
\hline Year $\times$ Site $\times$ Microsite & 2 & 1.14 & 1.14 & 2 & 1.59 & 0.205 \\
\hline
\end{tabular}

mean seed densities per $\mathrm{m}^{2}$ from CAN (canopy) to OBS (obstacle) to BG (bare ground), which were significant in 2008 (Fig. 2, A-D). In 2007, these differences were less pronounced with CAN and OBS soil seed banks similar in mean species richness at both sites (Fig. 2 , A-B). Mean seed densities per $\mathrm{m}^{2}$, however, were similar between CAN and OBS on DEG only (Fig. 2, C) which accounts for the significance in the interaction of site $\times$ microsite (Table 2 ). Pairwise comparisons of microsites sampled between sites revealed that the soil seed banks of DEG contained on average significantly more species and seeds than soil seed banks of REF across all microsites (Fig. 2, A-D).

On REF and DEG, there was a significant association between diaspore size and microsite (REF: $\chi^{2}=208.7, \mathrm{df}=6, p<0.001$, DEG: $\left.\chi^{2}=231.6, \mathrm{df}=6, p<0.001\right)$. On REF, the categories 'tiny' and 'CAN', 'small' and 'OBS', 'medium' and 'OBS', and 'large' and 'CAN' were more common than expected by chance. On DEG, small diaspores were clearly associated with CAN and BG, large diaspores showed to be associated with CAN (Fig. 3, A). A similar spatial pattern was found for mean numbers of seeds per diaspore size category and microsite (Fig. 3, B) with the abundance distribution of each size category significantly affected by the type of microsite at both study sites (GLM: $p<0.05$ ). At DEG, low-size obstacles of the open-matrix were as effective as shrubs in trapping small and tiny diaspores. Both size fractions, in particular tiny diaspores, were more common at DEG across microsites (Fig. 3, A-B).

\subsection{Spatio-temporal effects}

The factor year (i.e. soil seed bank response to high vs. low seasonal rainfall) had an overall significant effect on species richness and seed density (Table 2). The inter-annual variation in total species numbers was marginal on REF and more pronounced on DEG with an increase by one and eight species, respectively, from 2007 to 2008 (Table 1). Mean species numbers per sampling point increased significantly on both REF (ANOVA: $F=5.6, p=0.018$ ) and DEG (ANOVA: $F=6.0, p=0.015$ ) from 2007 to 2008 (Table 1). A similar temporal pattern was found for mean seed densities per $\mathrm{m}^{2}$, which were significantly higher in 2008 after the dry year on REF, and nearly significant higher on DEG (ANOVA: $F=10.9, p=0.001$ for REF, $F=3.6, p=0.051$ for DEG) (Table 1 ).

There was a significant interaction term of year $\times$ microsite indicating different responses of species richness and seed density of soil seed banks in the three microsites (Table 2). In general, the effect of year was positive on both soil seed bank attributes. However, the mean response of species richness and seed density rose by a similar amount in both years with regard to OBS and BG (species richness: 1.8(2007),1.9(2008), seed density: 1245.8 (2007), 1197.7 (2008)), indicating only a weak interaction with year. In contrast, respective soil seed bank attributes interacted with year on the factor level CAN, with an increase in mean species numbers of
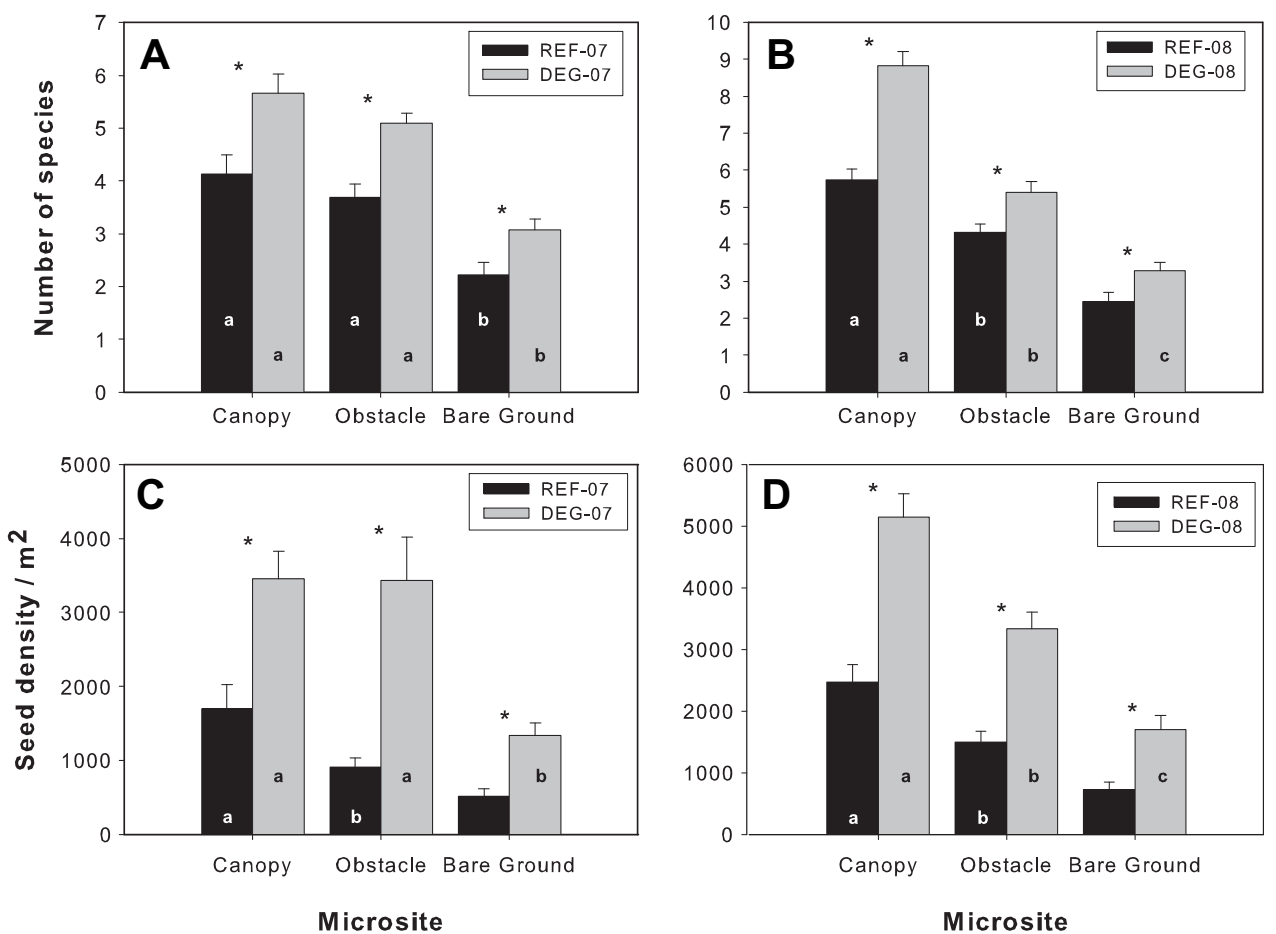

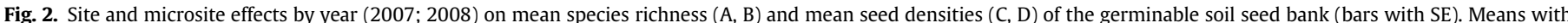

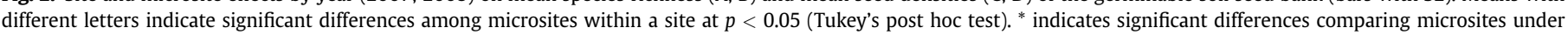
contrasting grazing intensity (site) at $p<0.05$ (one way ANOVA). 

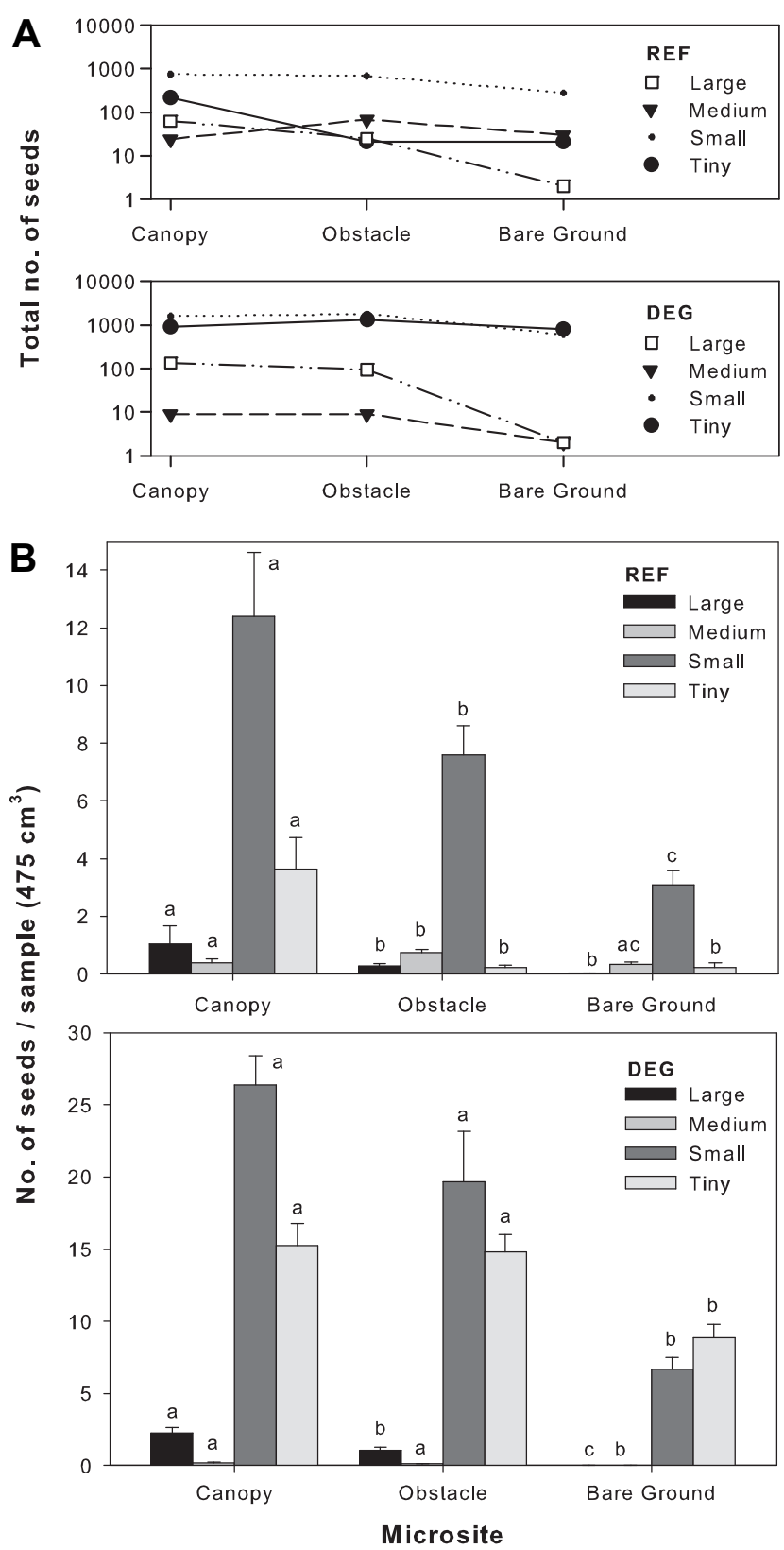

Fig. 3. Spatial distribution of diaspores by size among the sampled microsites according to their abundance in the germinable soil seed bank. (A) Total number of seeds in each diaspore size category, $(B)$ mean $( \pm S E)$ number of seeds per sample. Means with different letters indicate significant differences among microsites within a diaspore size category at $p<0.05$ (GLM pairwise comparisons). Data for 2007 and 2008 were pooled per site. $\mathrm{REF}=$ reference site, $\mathrm{DEG}=$ degraded site .

2.4 and in mean seed density per $\mathrm{m}^{2}$ of 1232.8 from 2007 to 2008 (Fig. 4).

The inter-annual variation in seed numbers consequently also affected patterns in size distribution of soil seed banks and life form distributions. Compared to 2007, in 2008 species-specific soil seed bank sizes were more evenly distributed across the size categories with more species present having smaller or medium-sized soil seed banks (Fig. 1). While some life forms showed different responses in degree of aggregation to year, such as annual grasses on REF and perennial forbs on REF and DEG, others remained fairly constant (Appendix 3).
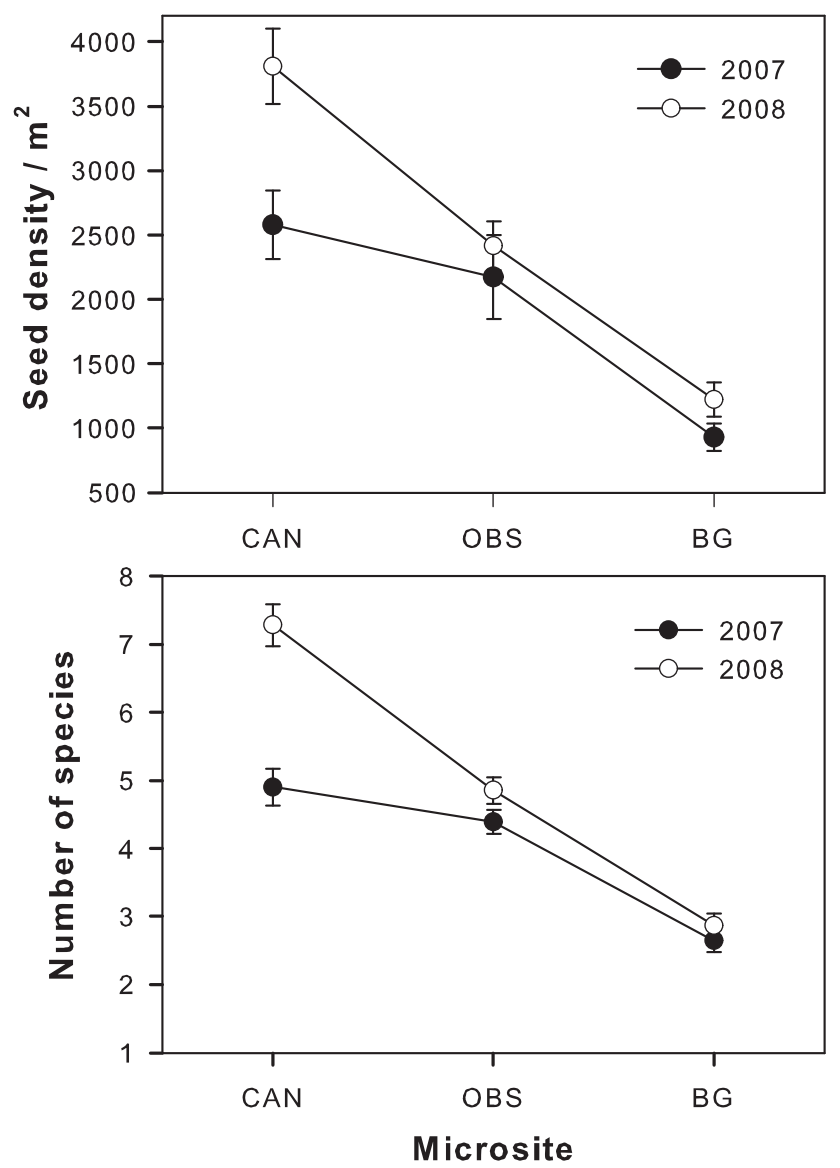

Fig. 4. Interaction plots for factor effects of 'year' (2 levels) and 'microsite' ( 3 levels) on species richness and seed density pooled for the study sites. Means with SE. CAN = canopy, $\mathrm{OBS}=$ obstacle, $\mathrm{BG}=$ bare ground

\section{Discussion}

\subsection{Responses of soil seed bank structure to grazing pressure}

The structure of soil seed banks is strongly influenced by surrounding communities and their production capacities (Kinucan and Smeins, 1992; Kassahun et al., 2009), which are shaped by the severity of grazing over extended time periods (Kinloch and Friedel, 2005a). Inconsistent results from studies regarding this topic commonly reflect local differences in climate, habitat and vegetation, as well as recent and past land management. However, the variation from the benchmark (REF) detected in this study seems to be rather unusual for arid and semiarid soil seed banks with both seed numbers and species numbers being increased under severe grazing.

Seed densities in the soil show varying response to intense grazing, and become either reduced, hardly affected or increased similar to our results (Table 3). The latter can be the consequence of grazing-induced selection for annual species that produce numerous seeds (Navie et al., 1996; Snyman, 2004; Willms and Quinton, 1995). This seed size-number tradeoff supports our finding that tiny and small diaspores were more numerous in the soil seed bank of the degraded rangeland (DEG) compared to the rangeland in good condition. Therefore, the higher seed densities at DEG may be explained by the changes in the frequency of diaspore sizes, which are related to changes in species composition (Osem et al., 2006). Although the botanical composition of the soil seed 
Table 3

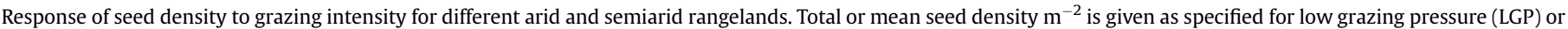
high grazing pressure (HGP). Ranges of seed densities indicate different habitat types or seasons sampled.

\begin{tabular}{|c|c|c|c|c|c|c|c|}
\hline Vegetation type & Location & Rainfall (mm/a) & Climate & Seed density $\mathrm{m}^{-2}$ LGP & Seed density $\mathrm{m}^{-2} \mathrm{HGP}$ & Response & Reference \\
\hline Shrubby grassland & South Africa & 341 & semiarid & n.s. & $6780-13230^{*}$ & & Jones and Esler (2004) \\
\hline Grassland & South Africa & 560 & semiarid & $28-58^{*}$ & $40-128^{*}$ & + & Snyman $(2004)^{*}$ \\
\hline Grassy woodland & Australia & 450 & semiarid & $9900^{* *}$ & $15500^{* *}$ & + & Navie et al. (1996) \\
\hline Shrubby grassland & Namibia & 150 & arid & $960-1450^{*}$ & $2650-3180^{*}$ & + & This study \\
\hline Shrubland & Israel & 305 & semiarid & $\sim 4000-18100^{* *}$ & $\sim 2500-9500^{* *}$ & - & Osem et al. (2006) $)^{* *}$ \\
\hline Grassland & Israel & 570 & semiarid & $10180^{* *}$ & $6890^{* *}$ & - & Sternberg et al. (2003) \\
\hline $\begin{array}{l}\text { Shrubby grassland, } \\
\text { bushland }\end{array}$ & Ethiopia & $110-600$ & arid-semiarid & $910^{*}$ & $400^{*}$ & - & Solomon et al. (2006) \\
\hline $\begin{array}{l}\text { Grass-, shrub-, } \\
\text { bushland }\end{array}$ & Ethiopia & $200-300^{*}$ & arid & $600-700^{*}$ & $320-480^{*}$ & - & Kassahun et al. (2009) \\
\hline Grassland & North America & 577 & semiarid & $3880-4410^{* *}$ & $2250-3880^{* *}$ & I & Kinucan and Smeins (1992) \\
\hline Shrubby grassland & Australia & $190-270$ & arid & n.s. & n.s. & l & Kinloch and Friedel (2005a) \\
\hline Shrubland & Australia & 215 & arid & $12750-28970^{* *}$ & $11600-13350^{* *}$ & I & Meissner and Facelli (1999) \\
\hline
\end{tabular}

Rainfall: ${ }^{*}=$ total instead of mean annual rainfall.

Seed density: ${ }^{*}=$ mean seed density $\mathrm{m}^{-2},{ }^{* *}=$ total seed density $\mathrm{m}^{-2}$, n.s. $=$ not specified.

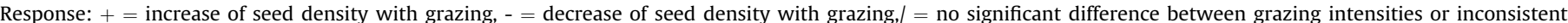
patterns.

Reference: ${ }^{*}=$ seed densities for graminoids, ${ }^{* *}=$ seed densities for annuals.

bank is similar across the fence-line regarding the most common species, there are profound shifts in species-specific abundance patterns (Dreber, unpublished data). The main difference in seed density found in comparing REF and DEG was caused by two annuals, namely the small-seeded Indigastrum argyroides and tinyseeded Trianthema parvifolia, producing extremely large soil seed banks (>1000 seeds), as shown by the frequency distribution of seed numbers per species. The increased abundance of such species in degraded habitats is facilitated by reduced interspecific competition through grazing pressure on palatable perennials (Bestelmeyer et al., 2003), and their improved colonization, establishment and survival ability (Navie and Rogers, 1997; Osem et al., 2006; Rees et al., 2001). Unfortunately, we were not able to test the potential effect of postdispersal removal of seeds by rodents and ants. Hoffmann and Zeller (2005) found rodents to be less abundant on DEG than on REF, which could have contributed to the difference in seed densities (Nelson and Chew, 1977), although only for larger seeds, attractive to rodents. Ants also can have a considerable effect on seed densities of large-seeded species by selective harvesting (Azcárate and Peco, 2006) but neither the densities of ant colonies nor that of collected seeds necessarily differ with grazing intensity or rangeland condition as shown for another Karoo ecosystem (Milton and Dean, 1993). In addition, larger seeds constituted the smallest diaspore fraction throughout the study sites and overall seed densities increased over time. Thus, we assume the predation effect by ants and/or rodents to be of minor importance for the comparison of study sites.

Contrary to our results, species numbers in soil seed banks are often reported to decrease with grazing intensity or to show no clear response (Kinucan and Smeins, 1992; Meissner and Facelli, 1999; Snyman, 2004). In the latter, between-site variability rather than grazing intensity can be the main cause of variation in species numbers (Kassahun et al., 2009; Kinloch and Friedel, 2005a). Despite intense grazing, the level of disturbance at DEG may still have led to higher species richness in relation to the understocked REF, due to a reduction of the dominant competitors according to Connell's (1978) Intermediate Disturbance Hypothesis. Grazing at DEG reduced profoundly the competitively dominant perennial grasses, and additionally altered soil surface conditions. Thus, the higher mean species numbers in the soil seed bank of DEG may relate to a disturbance regime associated with environmental changes providing opportunities for more species to colonize bare soil and eroded patches (Landsberg et al., 2002).

\subsection{Responses of spatial soil seed bank patterns to grazing pressure}

When comparing soil seed banks of different microsites, seed abundances underlie necessary variation caused by the size of related wind shadows and traps (DeFalco et al., 2009; Nelson and Chew, 1977; Reichman, 1984). In our study, the additional pooling of samples collected from different physical entities within the microsite class 'OBS' certainly increased the variance in our data. Nevertheless, patterns in the soil seed bank and the causal connection with the heterogeneity in microsites were unambiguous within-site and consistent over the grazing regimes. The results corroborate previous generalizations of seed distributions in arid ecosystems (Kemp, 1989). First, most species had small seed banks and only a few species had larger ones, supporting the assumption of an underlying general assemblage rule in community composition as found for North American deserts (Guo et al., 1999). Second, the spatial distribution of seeds was generally aggregated as found in various other arid and semiarid ecosystems (De Villiers et al., 2003; Kinucan and Smeins, 1992; Reichman, 1984). Third, species numbers and seed densities decreased from shrub canopies to small obstacles to bare ground. Seeds moved by wind or water are easily trapped under shrubs and may accumulate beneath plant structures and rocks (Flores and Jurado, 2003), as shown in this study. Soil seed banks of bare ground were seed limited and consisted nearly exclusively of tiny seeded and smallseeded species, confirming that such wind-exposed areas with small surface particle size are able to trap only diaspores of this size fraction (Chambers et al., 1991).

Considering aboveground differences in rangeland condition when comparing the study sites, one would expect the availability of microsites for seed accumulation would be affected (Kinloch and Friedel, 2005b), and thus the spatial patterning of the soil seed bank. While shrub cover at DEG was similar to REF, on a small scale, grazing reduced grass tussocks and litter quantity. This might indicate a dysfunction of the system in terms of decreased ability to trap and store seeds in the inter-shrub matrix (Simons and Allsopp, 2007). However, our results suggest that there was no profound effect on soil seed bank patterning in itself by heavy grazing and that the degraded ecosystem still was efficient in seed entrapment. As the stone cover was higher at DEG, likely due to blown out fine material, it seems in turn that this property accounted for the maintenance of seed entrapment ability in the open matrix.

The interaction of microsites and diaspore sizes demonstrated that diaspore traits play a role in soil seed bank patterning. Seed 
distribution pattern shows, however, interspecific differences linked to seed size and diaspore morphology (Li et al., 2009). The effect of diaspore size on soil seed bank patterning in response to microsite, but also grazing, might therefore be confounded by size correlations between plants, seeds and diaspores (Osem et al., 2006). Though severe grazing did not interfere with the identified overall pattern in seed distribution, it had an indirect effect on quantitative aspects in seed dispersion by favoring the abundance of certain diaspore sizes and providing a more open habitat structure. The latter likely causes an enhanced seed flow from the open into vegetated patches (Osem et al., 2007), whereas the high abundance of grass tussocks on REF restricts secondary movement of most seeds to short distances. Thus, seeds are likely distributed more evenly among obstacles resulting in lower densities at the single patch. We therefore conclude that both the seed sizenumber tradeoff characteristic for DEG and the condition of the physical environment contribute to the differences in the number of seeds and species per microsite between the study sites.

In conclusion, our results suggest that the physical environment necessary for controlling secondary dispersal is maintained at DEG and is similar to a non-degraded system, even after 30 years of uncontrolled and continuous grazing. In shrublands with much bare ground, small physical barriers like surface rocks can take up the function of grass tussocks in trapping and storing seeds of small-seeded and tiny-seeded species.

\subsection{Responses of soil seed banks to rainfall pattern}

The overall increase in species richness and seed density from 2007 to 2008 accounted for a persistence of structural differences between the study sites. In addition, the spatial patterning of seeds by microsites was maintained over the sampling period. Similarly, Reichman (1984) reported that despite significant variation in seed densities within microsites between sampling dates, the order of microhabitats regarding seed densities remained nearly identical over a three year period. However, in the present study, there was hardly any replenishment of the soil seed bank in the dry year 2007, and therefore the significant increase of readily germinable seeds in time and over microsites is rather counterintuitive. There is no overall plausible explanation for this pattern. Soil seed banks from both years were likely determined by the proportion of seeds, which persisted from the good growing season in 2006 and earlier. Thus, it appears that at least short-term persistent soil seed banks are common in this part of the Nama Karoo, and locally, seed loss from the system over time, e.g. through predation, was low. Conversely, the lower species numbers and seed densities found in 2007 imply that a certain proportion of seeds from previous seasons had remained dormant, but were released from dormancy in 2008 after the dry year. Proportional releases of seeds from dormancy over time are commonly observed among annual herbs and graminoids from arid and semiarid environments in adaptation to unreliable rainfall patterns (Gutterman, 2000; Veenendaal et al., 1996), which can have an additive effect on the proportion of readily germinable seeds following a year of bad conditions for germination (Philippi, 1993). Indeed, these functional groups accounted, almost entirely, for the seed carryover after the bad growing season (54.8\% and $46.9 \%$ of species at REF and DEG, respectively), whereas large-seeded species like the shrubs $C$. capitata and $P$. spinosum emerged exclusively from samples collected in 2008. However, persistent soil seed banks and dormancy patterns can explain only partially the increased seed densities in 2008. On the microsite scale, our results showed that the soil seed bank structure responded differently to sampling year, with shrubs accounting for most of the between-year differences in seed densities. It seems reasonable that due to low aboveground cover during the dry year of 2007, redistribution of seed containing material by wind was relatively pronounced on either side of the fence, which is likely to have increased deposition rates of seeds underneath shrubs over time. Similar to our findings, Quevedo-Robledo et al. (2010) report a higher difference in soil seed bank density between bare ground and shrub patches after a drier than moister growing season and suggest that this is related to the functioning of shrubs in providing safe sites for annual plant reproduction during unfavorable climate.

\subsection{Conclusions}

Complementary to reported impacts of unsustainable land use and unreliable rainfall on vegetation of the arid Nama Karoo, this study has shown that also the structure of soil seed banks in terms of species richness and seed densities is altered after decades of uncontrolled and continuous grazing, as hypothesized. Overall, both condition and sequence of preceding rainfall seasons were likely to have a joint effect on soil seed banks of subsequent years. This and the selection for annual species under severe grazing lead to higher inter-annual, as well as seasonal variations in plant cover and biomass production, making the environment more vulnerable to erosion and farmers to livestock losses. However, despite aboveground degradation, microsites for seed retention were still available and the physical environment necessary for controlling seed dispersal was maintained. Our study highlights the significant role of even small physical barriers in contributing to the provision of diverse seed reserves under continuous grazing pressure, which is of relevance for bare land restoration in degraded rangelands of arid Namibia. More research is needed to investigate the germination behavior of species in the context of rainfall variation, as well as associated mitigation effects of safe sites.

\section{Role of the funding source}

BMBF provided funding but played no role in the design and execution of this study and in article preparation.

\section{Acknowledgements}

We thank the management of the Gellap-Ost Research Station and the Nuwefontein community for permission to work on their land and support during data collection, K. Baumgaertner from the Botanical Garden at the University of Hamburg for providing assistance during the germination trials, all students and colleagues who contributed to the completion of the study, and two anonymous reviewer for helpful comments on the manuscript. Funding was provided by the BIOTA Southern Africa project which is sponsored by the German Federal Ministry of Education and Research (BMBF) under promotion number 01 LC 0024A. The Namibian Ministry of Environment and Tourism (MET) kindly granted a research permit.

\section{Appendix 1}

Schematic representation of the sampling design, indicating the three sampling areas per study site (REF (reference); DEG (degraded)), three transects per sampling area, alternately positioned $1-\mathrm{m}^{2}$ sampling plots for bare ground (BG) and obstacles (OBS) along the transects, and sampling points for shrub canopies (CAN), OBS and BG. Per sampling plot ( $1-\mathrm{m}^{2}$ plot/shrub) five replicate soil cores of same volume were taken and pooled. 


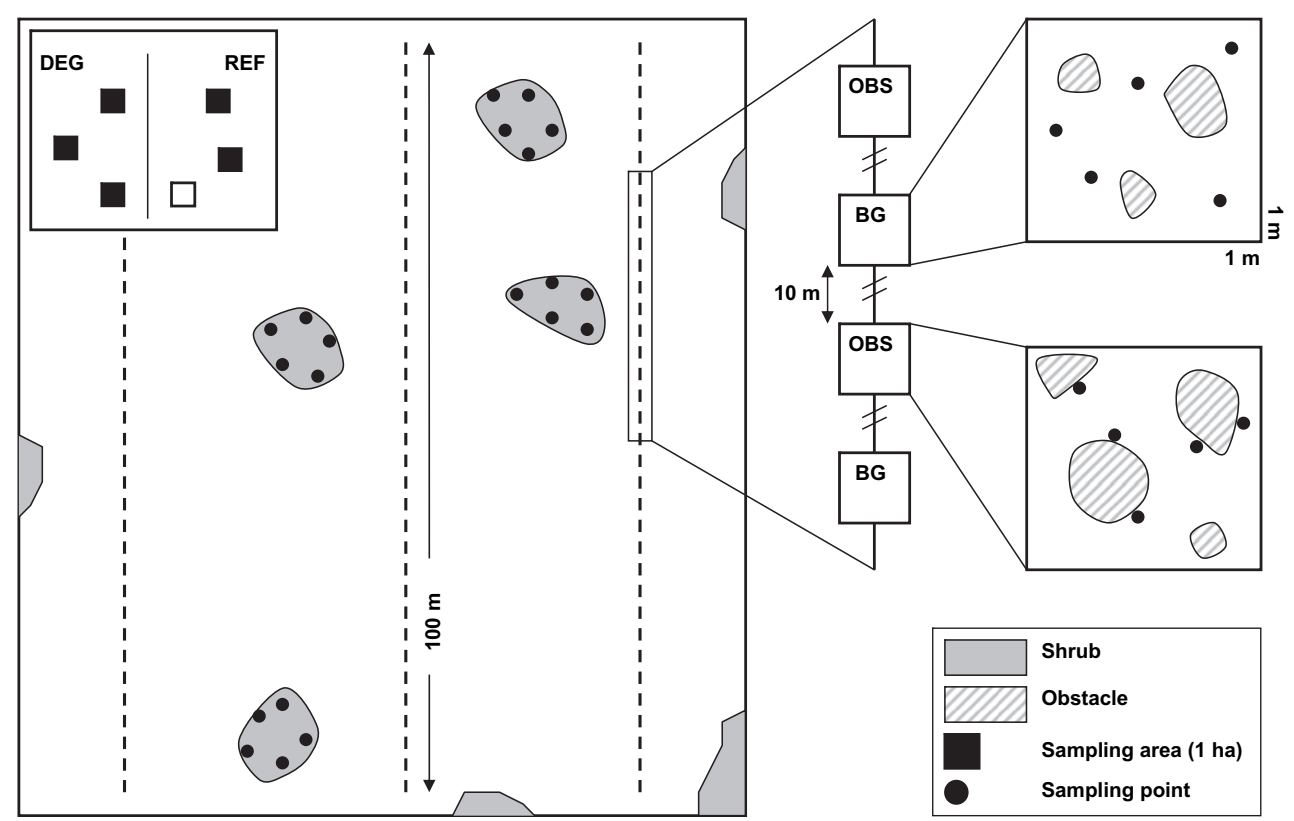

\section{Appendix 2}

\%cover of biological and physical entities in the inter-shrub matrix based on $n=1801-\mathrm{m}^{2}$ plots per study site. Data from both sampling years pooled. ${ }^{*}$ indicates significant differences between the study sites at $p<0.001$ (Mann-Whitney-U). REF $=$ reference site, $\mathrm{DEG}=$ degraded site.

\section{Appendix 3}

Spatial distribution of seeds categorized according to life form: mean number of germinants per sample over all microsites $(\bar{x})$, associated variance $\left(s^{2}\right)$, and variance-to-mean ratio $\left(s^{2} / \bar{x}\right)$ by year for grazing regime (site) and life forms (LF). REF = reference site, $\mathrm{DEG}=$ degraded site.
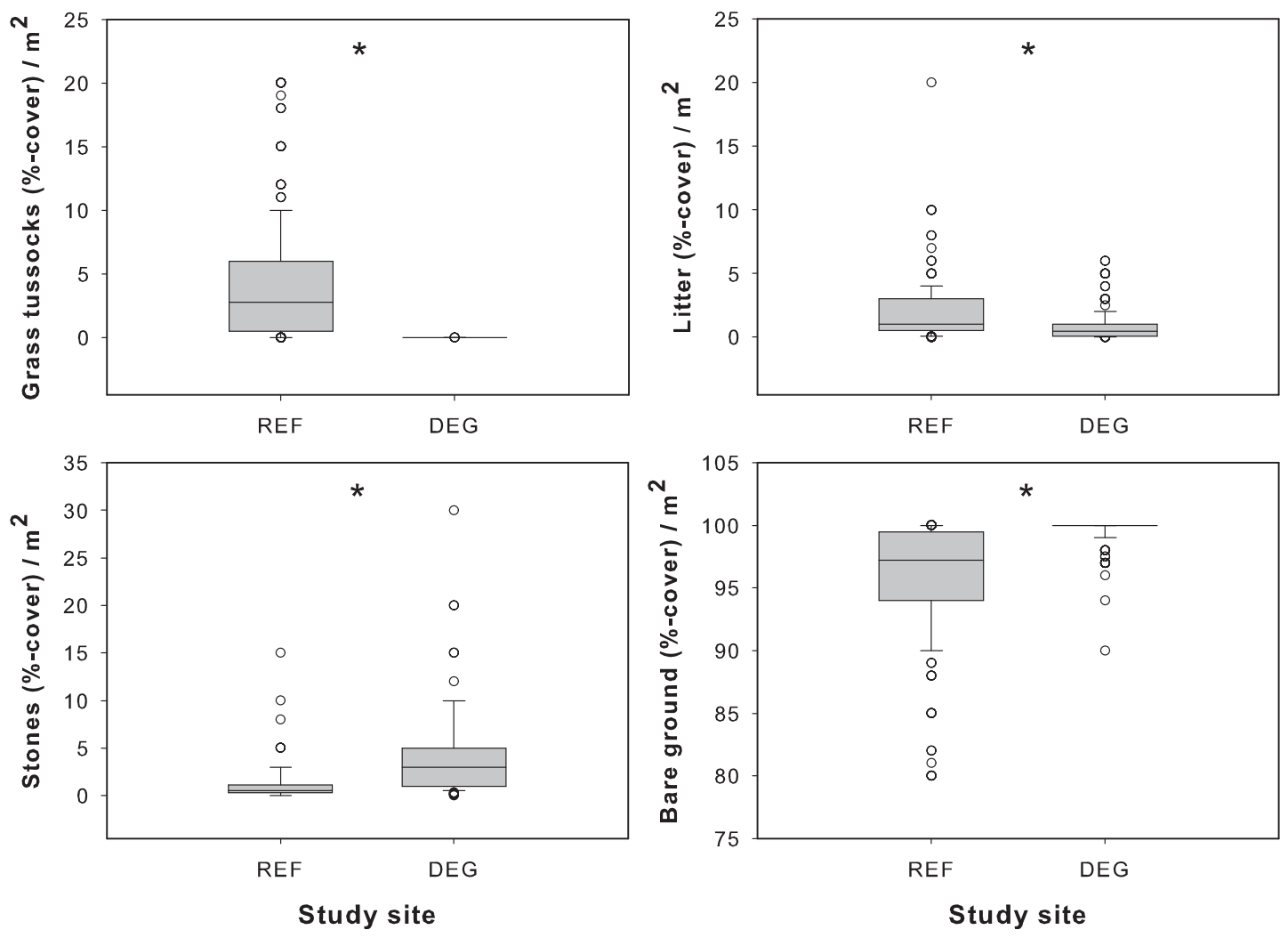


\begin{tabular}{|c|c|c|c|c|c|c|c|c|}
\hline & \multicolumn{4}{|l|}{2007} & \multicolumn{4}{|l|}{2008} \\
\hline & $\bar{x}$ & $s^{2}$ & $s^{2} / \bar{x}$ & Distribution & $\bar{x}$ & $s^{2}$ & $s^{2} / \bar{x}$ & Distribution \\
\hline \multicolumn{9}{|l|}{ Site } \\
\hline REF & 19.07 & 334.62 & 17.55 & clumped & 9.94 & 98.81 & 9.94 & clumped \\
\hline DEG & 46.34 & 1254.70 & 27.07 & clumped & 23.65 & 407.83 & 17.24 & clumped \\
\hline \multicolumn{9}{|l|}{$L F R E F$} \\
\hline annual grasses & 0.16 & 0.50 & 3.18 & clumped & 1.24 & 32.86 & 26.46 & clumped \\
\hline perennial grasses & 1.83 & 3.98 & 2.18 & clumped & 1.13 & 1.68 & 1.48 & clumped \\
\hline perennial forbs & 0.37 & 3.90 & 10.63 & clumped & 0.23 & 0.40 & 1.71 & clumped \\
\hline upright forbs & 8.87 & 172.37 & 19.44 & clumped & 13.53 & 182.27 & 13.48 & clumped \\
\hline dwarf shrubs & 0.03 & 0.03 & 0.97 & random & 0.03 & 0.02 & 0.98 & random \\
\hline Shrub & 0.01 & 0.01 & 1.00 & random & 0.53 & 11.39 & 21.36 & clumped \\
\hline \multicolumn{9}{|l|}{$L F D E G$} \\
\hline annual grasses & 1.23 & 4.29 & 3.50 & clumped & 1.70 & 9.61 & 5.65 & clumped \\
\hline perennial grasses & 0.03 & 0.03 & 0.97 & random & 0.06 & 0.06 & 1.37 & clumped \\
\hline perennial forbs & 22.22 & 916.12 & 41.24 & clumped & 26.44 & 327.79 & 12.40 & clumped \\
\hline upright forbs & 7.33 & 130.98 & 17.88 & clumped & 7.22 & 87.80 & 12.17 & clumped \\
\hline dwarf shrubs & 0.03 & 0.03 & 0.97 & random & 0.04 & 0.06 & 1.37 & clumped \\
\hline Shrub & 0.03 & 0.04 & 1.66 & clumped & 1.20 & 5.41 & 4.50 & clumped \\
\hline
\end{tabular}

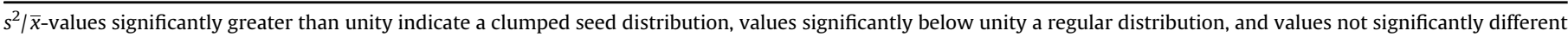
from unity a random pattern.

\section{References}

Azcárate, F., Peco, B., 2006. Effects of seed predation by ants on Mediterranean grassland related to seed size. Journal of Vegetation Science 17, $353-360$.

Bertiller, M.B., 1998. Spatial pattern of the germinable soil seed bank in northern Patagonia. Seed Science Research 8, 39-45.

Bestelmeyer, B.T., Brown, J.R., Havstad, K.M., Alexander, R., Chavez, R., Herrick, J.E., 2003. Development and use of state-and-transition models for rangelands. Journal of Range Management 56, 114-126.

Chambers, J.C., MacMahon, J.A., Haefner, J.H., 1991. Seed entrapment in alpine ecosystems: effects of soil particle size and diaspore morphology. Ecology 72 , 1668-1677.

Chambers, J.C., 2000. Seed movements and seedling fates in disturbed sagebrush steppe ecosystems: implications for restoration. Ecological Applications 10, 1400-1413.

Connell, J.H., 1978. Diversity in tropical rainforests and coral reefs. Science 199, 1302-1310.

DeFalco, L.A., Esque, T.C., Kane, J.M., Nicklas, M.B., 2009. Seed banks in a degraded desert shrubland: influence of soil surface condition and harvester ant activity on seed abundance. Journal of Arid Environments 73, 885-893.

De Villiers, A.J., van Rooyen, M.W., Theron, G.K., 2003. Similarity between the soil seed bank and the standing vegetation in the Strandveld succulent Karoo, South Africa. Land Degradation and Development 14, 527-540.

Dreber, N. How best to quantify soil seed banks in arid rangelands of the Nama Karoo? Environmental Monitoring and Assessment, 2010 (Epub ahead of print), doi:10.1007/s10661-010-1425-4.

Dytham, C., 2003. Choosing and Using Statistics. A Biologist's Guide, second ed. Blackwell Publishing, Oxford.

Falk, T., 2008. Communal Farmers' Natural Resource Use and Biodiversity Preservation. A New Institutional Economic Analysis from Case Studies in Namibia and South Africa. Cuvilier Verlag, Göttingen.

Flores, J., Jurado, E., 2003. Are nurse-protégé interactions more common among plants from arid environments? Journal of Vegetation Science 14, 911-916.

Germishuizen, G., Meyer, N.L., 2003. Plants of Southern Africa: An Annotated Checklist. Strelitzia 14. National Botanical Institute, Pretoria.

Guo, Q., Rundel, P.W., Goodall, D.W., 1998. Horizontal and vertical distribution of desert seed banks: patterns, causes, and implications. Journal of Arid Environments 38, 465-478.

Guo, Q., Rundel, P.W., Goodall, D.W., 1999. Structure of desert seed banks: comparisons across four North American desert sites. Journal of Arid Environments $42,1-14$.

Gutterman, Y., 2000. Environmental factors and survival strategies of annual plant species in the Negev Desert, Israel. Plant Species Biology 15, 113-125.

Hoffmann, A., Zeller, U., 2005. Influence of variation in land use intensity on species diversity and abundance of small mammals in the Nama Karoo, Namibia. Belgian Journal of Zoology 135, 91-96.

Jones, F.E., Esler, K.J., 2004. Relationship between soil-stored seed banks and degradation in eastern Nama Karoo rangelands (South Africa). Biodiversity and Conservation 13, 2027-2053.

Kassahun, A., Snyman, H.A., Smit, G.N., 2009. Soil seed bank evaluation along a degradation gradient in arid rangelands of the Somali region, eastern Ethiopia. Agriculture, Ecosystems and Environment 129, 428-436.

Kemp, P.R., 1989. Seed banks and vegetation processes in deserts. In: Leck, M.A., Parker, V.T., Simpson, R.L. (Eds.), Ecology of Soil Seed Banks. Academic Press, San Diego, pp. 257-281.
Kinloch, J.E., Friedel, M.H., 2005a. Soil seed reserves in arid grazing lands of central Australia. Part 1: seed bank and vegetation dynamics. Journal of Arid Environments $60,133-161$

Kinloch, J.E., Friedel, M.H., 2005b. Soil seed reserves in arid grazing lands of central Australia. Part 2: availability of 'safe sites'. Journal of Arid Environments 60,133-161.

Kinucan, R.J., Smeins, F.E., 1992. Soil seed bank of a semiarid Texas grassland under three long-term (36-years) grazing regimes. The American Midland Naturalist $128,11-21$.

Klintenberg, P., Seely, M., 2004. Land degradation monitoring in Namibia: a first approximation. Environmental Monitoring and Assessment 99, 5-21.

Kuiper, S.M., Meadows, M.E., 2002. Sustainability of livestock farming in the communal lands of southern Namibia. Land Degradation and Development 13,1-15.

Landsberg, J., James, C.D., Maconochie, J., Nicholls, A.O., Stol, J., Tynan, R., 2002. Scale-related effects of grazing on native plant communities in an arid rangeland region of South Australia. Journal of Applied Ecology 39, 427-444.

Li, F.R., Zhao, W.Z., Kang, L.F., Liu, J.L., Huang, Z.G., Wang, Q., 2009. Seed distribution of four co-occurring grasses around Artemisia halodendron shrubs in a sandy habitat. Acta Oecologica 35, 444-451.

Meissner, R.A., Facelli, J.M., 1999. Effects of sheep exclusion on the soil seed bank and annual vegetation in chenopod shrublands of South Australia. Journal of Arid Environments 42, 117-128.

Mendelsohn, J., Jarvis, A., Roberts, C., Robertson, T., 2002. Atlas of Namibia. A Portrait of the Land and Its People. Ministry of Environment and Tourism of Namibia. David Philip Publishers, Cape Town.

Milton, S.J., Dean, W.R.J.,1993. Selection of seeds by harvester ants (Messor capensis) in relation to condition of arid rangeland. Journal of Arid Environments 24, 63-74.

Msangi, J.P., 2004. Drought hazard and desertification management in the drylands of southern Africa. Environmental Monitoring and Assessment 99, 75-87.

Nathan, R., Muller-Landau, H.C., 2000. Spatial patterns of seed dispersal, their determinants and consequences for recruitment. Trends in Ecology and Evolution 15, 278-285.

Navie, S.C., Cowley, R.A., Rogers, R.W., 1996. The relationship between distance from water and the soil seed bank in a grazed semi-arid subtropical rangeland. Australian Journal of Botany 44, 421-431.

Navie, S.C., Rogers, R.W., 1997. The relationship between attributes of plants represented in the germinable seed bank and stocking pressure in a semi-arid subtropical rangeland. Australian Journal of Botany 45, 1055-1071.

Nelson, J.F., Chew, R.M., 1977. Factors affecting seed reserves in the soil of a Mojave desert ecosystem, RockValley, Nye County, Nevada. The American Midland Naturalist 97, 300-320.

Osem, Y., Konsens, I., Perevolotsky, A., Kigel, J., 2007. Soil seed bank and seedling emergence of Sarcopoterium spinosum as affected by grazing in a patchy semiarid shrubland. Israel Journal of Plant Science 55, 35-43.

Osem, Y., Perevolotsky, A., Kigel, J., 2006. Size traits and site conditions determine changes in seed bank structure caused by grazing exclusion in semiarid annual plant communities. Ecography 29, 11-20.

Palmer, A.R., Hoffman, M.T., 1997. Nama-karoo. In: Bowling, R.M., Richardson, D.M. Pierce, S.M. (Eds.), Vegetation of Southern Africa. CambridgeUniversity Press, Cambridge.

Peters, D.P.C., Bestelmeyer, B.T., Herrick, J.E., Fredrickson, E.L., Monger, H.C., Havstad, K.M., 2006. Disentangling complex landscapes: new insights into arid and semiarid system dynamics. BioScience 56, 491-501.

Petersen, A., 2008. Pedodiversity of Southern African Drylands. PhD thesis, University of Hamburg, Hamburg, Germany.

Philippi, T., 1993. Bet-hedging germination of desert annuals: beyond the first year. The American Naturalist 142, 474-487. 
Popp, A., Blaum, N., Jeltsch, F., 2009. Ecohydrological feedback mechanisms in arid rangelands: simulating the impacts of topography and land use. Basic and Applied Ecology 10, 319-329.

Quevedo-Robledo, L., Pucheta, E., Ribas-Fernández, Y., 2010. Influences of interyear rainfall variability and microhabitat on the germinable seed bank of annual plants in a sandy Monte Desert. Journal of Arid Environments 74, 167-172.

Quinn, G.P., Keough, M.J., 2002. Experimental Design and Data Analysis for Biologists. Cambridge University Press, Cambridge.

Rees, M., Condit, R., Crawley, M., Pacala, S., Tilman, D., 2001. Long-term studies of vegetation dynamics. Science 293, 650-655.

Reichman, O.J., 1984. Spatial and temporal variation of seed distributions in Sonoran Desert soils. Journal of Biogeography 11, 1-11.

Simons, L., Allsopp, N., 2007. Rehabilitation of rangelands in Paulshoek, Namaqualand: understanding vegetation change using biophysical manipulations. Journal of Arid Environments 70, 755-766.
Snyman, H.A., 2004. Soil seed bank evaluation and seedling establishment along a degradation gradient in a semi-arid rangeland. African Journal of Range and Forage Science 21, 37-47.

Solomon, T.B., Snyman, H.A., Smit, G.N., 2006. Soil seed bank characteristics in relation to land use systems and distance from water in a semi-arid rangeland of southern Ethiopia. South African Journal of Botany 72 $263-271$.

Sternberg, M., Gutman, M., Perevolotsky, A., Kigel, J., 2003. Effects of grazing on soil seed bank dynamics: an approach with functional groups. Journal of Vegetation Science 14, 375-386.

Veenendaal, E.M., Ernst, W.H.O., Modise, G.S., 1996. Effect of seasonal rainfal pattern on seedling emergence and establishment of grasses in a savanna in south-eastern Botswana. Journal of Arid Environments 32, 305-317.

Willms, W.D., Quinton, D.A., 1995. Grazing effects on germinable seeds on the fescue prairie. Journal of Range Management 48, 423-430. 